Pub. 1621

\title{
Assessment of Oxidative Status in Foot Diseases of Sheep
}

\author{
Ibrahim Yurdakul' \& Betul Apaydin Yildirim²
}

\begin{abstract}
Background: Oxidative stress plays an important role in the etiology and/or progression of various diseases in the livestock. The aim of this study was to investigate the relationship between foot diseases and oxidant and antioxidant levels, determining catalase (CAT) and glutathione peroxidase (GSH-Px) activities and malondialdehyde (MDA), nitric oxide (NO) and glutathione (GSH) concentrations in sheep with foot disease such as interdigital dermatitis, footrot and interdigital pouch infection (biflex canal inflammation).
\end{abstract}

Materials, Methods \& Results: In the study, a total of 70 sheep aged between 1 and 3, 20 sheep with interdigital dermatitis, 20 with foot-rot, 10 with interdigital pouch inflammation and 20 clinically healthy Akkaraman sheep, were used. The blood samples collected from the V. Jugularis of the sheep were centrifuged and their serums were obtained. MDA and NO levels of the sheep with interdigital dermatitis, footrot and interdigital pouch infection were found to be significantly higher than those of animals in the control group $(P<0.001)$. CAT activity was determined to be significantly lower in all diseased animals than in the animals in the control group $(P<0.001)$. GSH-Px and GSH levels were significantly lower in the animals with interdigital dermatitis than in the control group (respectively $P<0.001, \mathrm{P}<0.05$ ).

Discussion: Oxidative stress regulates the metabolic activity of some organs and plays an important role in productivity in livestock. The oxidative stress is reported that caused by the increase in the production of excessive free radicals resulting from the exposure of animals to various stress factors and by the weakening of the antioxidant defense has an important role in the pathogenesis of numerous diseases such as foot diseases. In the presence of various stress factors, the level of malondialdehyde (MDA) and nitric oxide (NO) increases. MDA is determine the degree of cellular damage in tissues. Nitric oxide is produced in large quantities by macrophages in case of bacterial infections and exhibits antibacterial properties against pathogenic microorganisms. For this reason, NO is very high levels in inflammatory diseases. Catalase (CAT), glutathione peroxidase (GSH-Px), and glutathione (GSH) is some of the important antioxidants and play an important role in the oxidative defense of tissues. In this study, the increase in serum MDA and NO levels was mostly found in interdigital dermatitis cases, then in footrot cases and finally in interdigital pouch infection cases. Serum CAT levels were found to be significantly lower than that of the control group $(P<0.001)$. In this study, the highest decrease in serum CAT levels was detected in interdigital dermatitis cases and followed by footrot cases and interdigital pouch infection cases, respectively. Serum GSH-Px and GSH levels were found to be significantly lower in interdigital dermatitis cases than those in the control group (respectively $P<0.001, P<0.05$ ). There was no statistically significant difference found between the serum GSH-Px and GSH levels of footrot and interdigital pouch infection cases, and the control group $(P>$ 0.05). We found that serum MDA and NO levels were found to significantly increase in sheep with foot disease and serum CAT levels were found to be significantly lower. The results of this research indicate that MDA, NO and CAT activities may be more reliable parameters than GSH-Px and GSH activities in order to determine oxidative stress in sheep with foot diseases. In conclusion, this study reveals that there is a relationship between foot diseases and oxidant/antioxidant balance in sheep and it shows that the oxidative stress and lipid peroxidation develop due to the increase of free radicals.

Keywords: oxidant, antioxidant, foot disease, sheep. 


\section{INTRODUCTION}

Lameness is a common cause of prosperous and economic concerns in many countries [26] and leads to serious economic losses both on the individual and herd basis by adversely affecting the yield of meat, milk and offspring [24].

Many factors play a role in the etiology of foot diseases in sheep, being both preparative and constructive. Preparatory factors include environmental factors such as the presence of systemic diseases in the herd, malabsorption, the order of housings, the suitability and hygiene of the ground structure, and pastureland conditions, and seasonal changes [11,22,30].

Constructive factors include infection factors such as Bacteroides nodosus and Fusobacterium necrophorum [24,30]. These infection factors have an important role in the formation of interdigital dermatitis which is the acute necrotic inflammation of the interdigital skin, in the formation of footrot which is characterized with the occurrence of a mild inflammation on interdigital skin, corium ungulae and other tissues, separation of capsula ungulae from corium ungulae over time, and necrosis of corium ungulae $[10,19]$ and also in the inflammation of the biflex canal (interdigital pouch infection), which is located between digiti [11].

Oxidants are the active oxygen derivatives of free radicals [8]. Oxidants and antioxidants are in equilibrium in organisms [1]. This balance is disturbed in favor of oxidants in cases when the intake of antioxidants is prevented, such as infection, inflammation, malabsorption, stress, exercise, metabolic and environmental factors, and leads to cellular damage in the living organism. This is defined as oxidative stress $[8,14,23,25]$.

Several defense mechanisms have been developed in organisms to prevent the damage on the cellular structure caused by free radicals, more specifically the ROS (Reactive Oxygen Species), and these mechanis$\mathrm{ms}$ are called antioxidant defense systems [20].

With this study, it was aimed to determine the effects of foot diseases such as interdigital dermatitis, footrot and interdigital pouch infection on the oxidative level in sheep.

\section{MATERIALS AND METHODS}

\section{Animals}

The study material consist of a total of 70 sheep aged between 1 and 3, of 20 with interdigital dermatitis, of 20 footrot, of 10 with interdigital pouch infection (a total of 50 sheep with foot diseases) and 20 clinically healthy Akkaraman sheep were used. The diseases in sheep which had lameness were diagnosed based on the information taken from the animal owners and the detailed clinical examinations of the foot in which lameness was observed. It was also observed that there were not any other clinical diseases other than a foot disease in sick sheep.

\section{Blood sampling}

For blood analysis, $10 \mathrm{~mL}$ of blood samples were collected in sterile tubes without anticoagulants from the V. Jugularis of healthy and sick sheep. Blood samples collected were incubated at room temperature for $30 \mathrm{~min}$, then centrifuged at $3.000 \mathrm{rpm}$ for $15 \mathrm{~min}$ and the serums were stored at $-20^{\circ} \mathrm{C}$ until the analysis.

\section{Serum biochemical analysis}

The levels of MDA [29], NO [13], CAT [9], GSH [27] and GSH-Px [21] from the serums obtained were measured using a spectrophotometer (model $\mu$ Quant MQX200) ${ }^{1}$ in accordance with the procedure.

\section{Statistical analysis}

The statistical evaluation of the data obtained in the study was performed using the Statistical Package for Social Sciences (SPSS) v20.0 software ${ }^{2}$. The obtained data were evaluated by variance analysis performed using one-way analysis of variance ANOVA and Tukey post hoc test. The data were given as average and the standard error of the average and $P<$ $0.05, P<0.001$ was considered as statistically significant difference.

\section{RESULTS}

Serum MDA, NO, CAT, and GSH-Px and GSH levels of healthy and sick sheep in which a foot disease was determined were listed in Table 1. In this study, serum MDA and NO levels were found to significantly increase in sheep with foot disease compared to those in the control group $(P<0.001)$. The increase in serum MDA and NO levels was mostly found in interdigital dermatitis cases, then in footrot cases and finally in interdigital pouch infection cases.

In all cases, serum CAT levels were found to be significantly lower than that of the control group $(P<0.001)$. The highest decrease in serum CAT levels was detected in interdigital dermatitis cases 
Table 1. MDA, NO, CAT, GSH-Px and GSH levels in foot disease $(n=50)$ and healthy sheep $(n=20)$. Results are expressed as mean \pm standard deviation.

\begin{tabular}{cccccc}
\hline Group & MDA $(\mathrm{nmol} / \mathrm{L})$ & $\mathrm{NO}(\mu \mathrm{mol} / \mathrm{L})$ & $\mathrm{CAT}(\mathrm{U} / \mathrm{L})$ & GSH-PX $(\mathrm{U} / \mathrm{L})$ & GSH $(\mathrm{nmol} / \mathrm{L})$ \\
\hline Control & $2.55 \pm 0.13^{\mathrm{d}}$ & $7.67 \pm 0.04^{\mathrm{d}}$ & $234.67 \pm 10.84^{\mathrm{a}}$ & $0.16 \pm 0.00^{\mathrm{a}}$ & $1.17 \pm 0.05^{\mathrm{a}}$ \\
Footrot & $7.45 \pm 0.10^{\mathrm{b}}$ & $10.26 \pm 0.13^{\mathrm{b}}$ & $149.87 \pm 7.17^{\mathrm{c}}$ & $0.15 \pm 0.00^{\mathrm{a}}$ & $1.08 \pm 0.02^{\mathrm{ab}}$ \\
$\begin{array}{c}\text { Interdigital } \\
\text { Dermatitis }\end{array}$ & $8.18 \pm 0.23^{\mathrm{a}}$ & $12.52 \pm 0.12^{\mathrm{a}}$ & $107.72 \pm 2.38^{\mathrm{d}}$ & $0.13 \pm 0.01^{\mathrm{b}}$ & $1.03 \pm 0.01^{\mathrm{b}}$ \\
$\begin{array}{c}\text { Interdigital } \\
\text { pouch infection }\end{array}$ & $6.25 \pm 0.19^{\mathrm{c}}$ & $8.70 \pm 0.26^{\mathrm{c}}$ & $196.99 \pm 9.98^{\mathrm{b}}$ & $0.16 \pm 0.00^{\mathrm{a}}$ & $1.17 \pm 0.02^{\mathrm{a}}$ \\
$P$ & $* * *$ & $* * *$ & $* * *$ & $* * *$ & $* *$ \\
\hline a.b,c,d Different superscripts letters indicate statistically significant differences $(* * P<0.05 * * * *<0.001)$ &
\end{tabular}

and followed by footrot cases and interdigital pouch infection cases, respectively.

Serum GSH-Px and GSH levels were found to be significantly lower in interdigital dermatitis cases than those in the control group (respectively $P<$ $0.001, P<0.05)$. There was no statistically significant difference found between the serum GSH-Px and GSH levels of footrot and interdigital pouch infection cases, and the control group $(P>0.05)$.

\section{DISCUSSION}

It is thought that oxidative stress regulates the metabolic activity of some organs and plays an important role in productivity in livestock [7]. Generally, stress factors affecting livestock are classified into two groups. Physiological stresses such as animals being housed in congested environments, problems with housing areas and animals exposure to unexpected adverse effects are included in the first group, and physical stress and environmental effects such as hunger, injury, diseases constitute the second group [3].

It is reported that the oxidative stress caused by the increase in the production of excessive free radicals resulting from the exposure of animals to various stress factors and by the weakening of the antioxidant defense $[7,8]$ has an important role in the pathogenesis of numerous diseases such as foot diseases, respiratory and joint diseases, sepsis, mastitis, acidosis, ketosis, enteritis and endoparasitic diseases in livestock $[6,13,26]$. Although there are various studies on oxidative stress in sheep, there are very few studies that examined the relationship between the oxidative stress and foot diseases in sheep such as interdigital dermatitis, footrot and interdigital pouch infection. For this reason, this study was conducted to measure the serum MDA, NO and GSH concentrations and CAT and GSH-Px activities in sheep with foot diseases such as interdigital dermatitis, footrot and interdigital pouch infection and to assess oxidative stress level.

In the presence of various stress factors, the level of malondialdehyde (MDA), the end product of lipid peroxidation, increases [3]. MDA is one of the most important biochemical markers used to determine the degree of cellular damage in tissues $[20,23]$. The level of MDA has been reported to increase in studies conducted with cattle with foot-and-mouth disease $[12,17]$ and with calves with different inflammatory diseases such as arthritis and omphalitis [5,31]. In this presented study, serum MDA levels were found to increase significantly $(P<0.001)$ in sheep with interdigital pouch infection, footrot and interdigital dermatitis compared to healthy sheep, which is consistent with the above studies. This increase in MDA levels can be suggested as an indication of excessive free radical production which causes cellular damage in tissues.

Free nitrogen derivatives among free radicals that are called RNS are nitric oxide (NO) and peroxynitrite [25]. NO is a free radical that mediates both physiological and pathological events in the body [28]. NO has been reported to suppress the immune system, despite its primary defense role against bacteria, viruses and parasites. For this reason, NO may be protective or dangerous for tissues depending on its concentration [4]. Nitric oxide is produced in large quantities by macrophages in case of bacterial infections and exhibits antibacterial properties against pathogenic microorganisms [5]. Nitric oxide has an inflammation inhibitor effect [16]. Because of this property, it is at very high levels in inflammatory diseases and is converted to peroxynitrite, which is a strong oxidizing agent for 
tissues and organs, combining with superoxide [23]. NO levels in synovial fluid of 20 calves with arthritis were reported to be more significant than the control group [31]. In a study of cattle with foot-and-mouth disease, serum NO levels were reported to be higher than in the control group, which was reported to be related to NO release and stimulation of the immune system $[4,28]$. In this study, when NO levels in interdigital dermatitis, footrot and interdigital pouch infection cases were compared with those in the control group, a statistically significant increase $(P<0.001)$ was found. Depending on this increase, it can be suggested that NO plays an active role in body defense against pathogens that cause foot diseases.

Some of the important antioxidants that prevent the accumulation of free radicals and the onset of lipid peroxidation include catalase (CAT), glutathione peroxidase (GSH-Px), and glutathione (GSH) [18]. Catalase has different catalytic activity in various tissues [32]. CAT and GSH-Px play an important role in the oxidative defense of tissues, catalyzing the reduction of hydrogen and lipid peroxides in all organs. The affinity of CAT enzyme to hydrogen peroxide is higher than that of GSH-Px [32]. Furthermore, changes in CAT and GSH-Px activities are considered as indicators of oxidative stress [6,25]. Glutathione (GSH), a non-enzymatic antioxidant, is important in protecting the body against the oxidative stress, having an important role in the inactivation of free radicals [15] and its level decreases during the oxidative stress [31]. In six rams with foot lesion, the level of ROS was found to be significantly higher and the level of antioxidant was found to be lower than in the control group [26]. They reported that the increase in ROS and the decrease in antioxidants were the indicators of oxidative stress in rams with foot lesion. In 18 calves with severe foot lesion, CAT, GSH-Px and GSH levels in the experimental group were significantly decreased compared to the control group in parallel with the increase in lipid peroxidation during oxidative stress. [2]. It has been reported in foot-and-mouth disease (FMD) cattle that GSH-Px is reduced and that this reduction is due to tissue damage resulting from increased oxidant production in the sick animals in order to avoid the severity of GSH-Px consumption [17].

In this study, there was a statistically significant $(P<0.001)$ decrease found in serum CAT levels in interdigital dermatitis, footrot and interdigital pouch infection cases compared to those in the control group. This decrease in the serum CAT levels may be interpreted as the excessive use of CAT activity as an antioxidant due to the effect of excessive free radicals resulting from the inflammation in foot diseases.

In addition, it was found that serum GSH-Px and GSH levels showed a decrease in interdigital dermatitis and footrot cases compared to those in the control group, whereas there was no difference observed in interdigital pouch infection cases compared to the control group. This decrease in GSH-Px and GSH levels was found to be statistically significant only in interdigital dermatitis cases (respectively $P<0.001, P$ $<0.05)$ but not statistically significant in footrot and interdigital pouch infection cases $(P>0.05)$.

\section{CONCLUSIONS}

The results obtained show that the oxidative stress and the lipid peroxidation develop due to the increase of free radicals in sheep with foot diseases. It is also thought that MDA, NO and CAT activities may be more reliable parameters than GSH-Px and GSH activities in order to determine oxidative stress in sheep with foot diseases.

As a result, it was concluded that the oxidative damage develops in sheep during foot diseases such as interdigital dermatitis, footrot and interdigital pouch infection, and consequently, the administration of extra antioxidants to sick sheep may contribute to the improvement of the disease and the reduction of treatment costs.

\section{MANUFACTURERS}

${ }^{1}$ BioTek Instruments Inc. Winooski,VT, USA. ${ }^{2}$ IBM Corp. Armonk, NY, USA.

Declaration of interest. The authors report no conflicts of interest. The authors alone are responsible for the content and writing of the paper. 


\section{REFERENCES}

1 Aktas M.S., Kandemir F.M., Kirbas A., Hanedan B. \& Aydin M.A. 2017. Evaluation of oxidative stress in sheep infected with Psoroptes ovis using total antioxidant capacity, total oxidant status, and malondialdehyde level. Journal of Veterinary Research. 61(2): 197-201.

2 Al-Qudah K.M. \& Ismail Z.B. 2012. The relationship between serum biotin and oxidant/antioxidant activities in bovine lameness. Research in Veterinary Science. 92(1): 138-141.

3 Arslan H.H., Nisbet C., Sarımar D., Cenesiz S. \& Cenesiz M. 2008. Effects of combination of asetylmethionine, L-carnitine, vitamin $\mathrm{E}$ and vitamin $\mathrm{B}_{12}$ on some clinical, haematological and biochemical parameters in cattle. Van Veterinary Journal. 19(1): 9-14.

4 Bozukluhan K., Atakisi E. \& Atakisi O. 2013. Nitric oxide levels, total antioxidant and oxidant capacity in cattle with foot-and-mouth-disease. The journal of the Faculty of Veterinary Medicine, University of Kafkas. 19(1): 179-181.

5 Bozukluhan K., Merhan O., Ogun M., Cihan M. \& Gokce G. 2016. Determination of the levels of some oxidative stress parameters in calves with omphalitis. Fırat Üniversitesi Să̆lık Bilimleri Veteriner Dergisi. 30(2): 79-81.

6 Celi P. 2010. The role of oxidative stress in small ruminants' health and production. Revista Brasileira Zootecnia. 39: 348-363.

7 Celi P., Trana A.D. \& Claps S. 2010. Effects of plane of nutrition on oxidative stress in goats during the peripartum period. The Veterinary Journal. 184(1): 95-99.

8 Eken A. 2016. Deney Hayvanı Rat. Ankara: Derman medical, pp.160-169.

9 Goth L. 1991. A simple method for determenation of serum catalase activity and revision of serum catalase activity and revision of reference range. Clinica Chimica Acta. 196(2-3): 143-152.

10 Groneng G.M., Vatn S., Kristoffersen A.B., Nafstad O. \& Hopp P. 2015. The potential spread of severe footrot in Norway if no elimination programme had been initiated: A simulation model. Veterinary Research. 46: 10.

11 Kamiloglu A. 2014. Çiftlik Hayvanlarında Ayak Hastalıkları. Ankara: Medipres, pp.287-295.

12 Khoshvaghti A., Askari A., Nazifi S. \& Ghane M. 2014. Evaluation of some antioxidant enzymes in cattle infected with foot and mouth virüs. Journal of Faculty of Veterinary Medicine, İstanbul Univiversity. 40(1): 70-75.

13 Lykkesfeldt J. \& Svendsen O. 2007. Oxidants and antioxidants in disease: Oxidative stress in farm animals. The Veterinary Journal. 173(3): 502-511.

14 Marreiro D.N., Cruz K.J.C., Morais J.B.S., Beserra J.B., Severo J.S. \& Oliveira A.R.S. 2017. Zinc and oxidative stress: Current mechanisms. Antioxidants. 6(2): 24.

15 Mates J.M. 2000. Effects of antioxidant enzymes in the molecular control of reactive oxygen species toxicology. Toxicology. 153(1): 83-104.

16 Miranda K.M., Espey M.G. \& Wink D.A. 2001. A rapid, simple spectrophotometric method for simultaneous detection of nitrate and nitrite. Nitric Oxide. 5(1): 62-71.

17 Nath R., Prasad R.L. \& Sarma S.2014. Oxidatıve stress biomarkers in cross bred cows affected with foot and mouth disease. Indian Journal of Animal Research. 48(6): 628-632.

18 Nimse S.B. \& Pal D. 2015. Free radicals, natural antioxidants, and their reaction mechanisms. Royal Society of Chemistry Advances. 35(5): 27986-28006.

19 Olechnowicz J. \& Jaskowski J.M. 2011. Lameness in small ruminants. Medycyna Weterynaryjna. 67(11): 715-719.

20 Ozcan O., Erdal H., Cakirca G. \& Yonden Z. 2015. Oxidative stress and its impacts on intracellular lipids, proteins and DNA. Journal of Clinical and Experimental Investigations. 6(3): 331-336.

21 Paglia D.E. \& Valentine W.N. 1967. Studies on the quantitative and qualitative characterization of erythrocyte glutathione peroxidase. Journal of Laboratory and Clinical Medicine. 70(1): 158-169.

22 Sagliyan A., Gunay C. \& Koparir M. 2003. The role of copper and zinc in the etiology of foot-rot of sheep in Elazı $\breve{g}$ Region. Turkish Journal of Veterinary Surgery. 9(1-2): 11-16.

23 Sezer K. \& Keskin M. 2014. Role of the free oxygen radicals on the pathogenesis of the diseases. Firat Üniversitesi Să̆lık Bilimleri Veteriner Dergisi. 28(1): 149-156.

24 Stilwell G. 2016. Lameness in small ruminants-economical and welfare impact. In: Proceedings of the Australian Veterinary Association Annual Conference (Adelaide, Australia). pp.821-826.

25 Tabakoglu E. \& Durgut R. 2013. Oxidatıve stress in veterinary medicine and effects in some important diseases. Adana Veteriner Kontrol Enstitüsü Müdürlüğ̈̈ Dergisi. 3(1): 69-75. 
26 Talukder S., Gabai G. \& Celi P. 2015. The use of digital infrared thermography and measurement of oxidative stress biomarkers as tools to diagnose foot lesions in sheep. Small Ruminant Research. 127: 80-85.

27 Tietze F. 1969. Enzymic method for quantitavite determination of nanogram amounts of total and oxidized glutathione. Analytical Biochemistry. 27(3): 502-522.

28 Yarim G.F., Nisbet C., Cenesiz S. \& Coskuner A. 2006. The investigation of the effect of foot and mouth disease on nitric oxide levels and adenosine deaminase activity in sheep. Veterinary Journal of Ankara University. 53(2): 161-164.

29 Yoshioka T., Kawada K., Shimada T. \& Mori M. 1979. Lipid peroxidation in maternal and cord blood and protective mechanism against activated- oxygen toxicity in the blood. American Journal of Obstetrics \& Gynecology. 135(3): 372-376.

30 Yurdakul I. 2018. Investigation of prevalance of foot diseases in sheep in Sivas Region. Ataturk University Journal of Veterinary Sciences. 13(1): 77-83.

31 Yurdakul G. \& Saritas Z.K. 2013. Evaluation of clinic, radiographic and some biochemical blood serum and synovial fluid parameters of arthritis cases in calves. Kocatepe Veterinary Journal. 6(2): 13-22.

32 Zengin K., Mert H. \& Mert N. 2017. Catalase activity and the levels of MDA, AOPP in sheeps with subclinical mastitis. Research in: Agricultural \& Veterinary Sciences. 1(1): 5-11. 